\title{
Skeletal muscle and hepatic insulin signaling is maintained in heat-stressed lactating Holstein cows
}

\author{
G. Xie, ${ }^{*}$ L. C. Cole,† L. D. Zhao, ${ }^{*}$ M. V. Skrzypek,† S. R. Sanders, † M. L. Rhoads, ${ }^{\star}$ L. H. Baumgard,† \\ and R. P. Rhoads*1 \\ *Department of Animal and Poultry Science, Virginia Tech University, Blacksburg 24061 \\ †Department of Animal Science, University of Arizona, Tucson 85721 \\ ‡Department of Animal Science, lowa State University, Ames 50014
}

\section{ABSTRACT}

Multiparous cows $(\mathrm{n}=12 ;$ parity $=2 ; 136 \pm 8 \mathrm{~d}$ in milk, $560 \pm 32 \mathrm{~kg}$ of body weight) housed in climate-controlled chambers were fed a total mixed ration (TMR) consisting primarily of alfalfa hay and steam-flaked corn. During the first experimental period (P1), all 12 cows were housed in thermoneutral conditions $\left(18^{\circ} \mathrm{C}\right.$, $20 \%$ humidity) with ad libitum intake for 9 d. During the second experimental period (P2), half of the cows were fed for ad libitum intake and subjected to heatstress conditions [WFHS, $\mathrm{n}=6$; cyclical temperature 31.1 to $38.9^{\circ} \mathrm{C}, 20 \%$ humidity: minimum temperature humidity index $(\mathrm{THI})=73$, maximum $\mathrm{THI}=80.5]$, and half of the cows were pair-fed to match the intake of WFHS cows in thermal neutral conditions (TNPF, $\mathrm{n}=6$ ) for $9 \mathrm{~d}$. Rectal temperature and respiration rate were measured thrice daily at 0430, 1200, and 1630 $\mathrm{h}$. To evaluate muscle and liver insulin responsiveness, biopsies were obtained immediately before and after an insulin tolerance test on the last day of each period. Insulin receptor (IR), insulin receptor substrate 1 (IRS1), AKT/protein kinase B (AKT), and phosphorylated AKT (p-AKT) were measured by Western blot analyses for both tissues. During P2, WFHS increased rectal temperature and respiration rate by $1.48^{\circ} \mathrm{C}$ and $2.4-$ fold, respectively. Heat stress reduced dry matter intake by $8 \mathrm{~kg} / \mathrm{d}$ and, by design, TNPF cows had similar intake reductions. Milk yield was decreased similarly $(30 \%)$ in WFHS and TNPF cows, and both groups entered into a similar $(-4.5 \mathrm{Mcal} / \mathrm{d})$ calculated negative energy balance during P2. Insulin infusion caused a less rapid glucose disposal in P2 compared with P1, but glucose clearance did not differ between environments in P2. In liver, insulin increased p-AKT protein content in each period. Phosphorylation ratio of AKT

Received September 29, 2015.

Accepted January 21, 2016.

${ }^{1}$ Corresponding author: rhoadsr@vt.edu increased $120 \%$ in each period after insulin infusion. In skeletal muscle, protein abundance of the IR, IRS, and AKT remained stable between periods and environment. Insulin increased skeletal muscle p-AKT in each period, but the phosphorylation ratio (abundance of phosphorylated protein:abundance of total protein) of AKT was decreased in P2 for TNPF animals, but not during WFHS. These results indicate that mild systemic insulin resistance during HS may be related to reduced nutrient intake but skeletal muscle and liver insulin signaling remains unchanged.

Key words: heat stress, insulin, hyperthermia, dairy cow

\section{INTRODUCTION}

Although advances in environmental cooling systems ameliorate production losses during summer months, heat stress continues to cost the US dairy industry approximately $\$ 1$ billion annually (St-Pierre et al., 2003). Dairy cattle acclimation to elevated environmental temperature involves numerous mechanisms intended to reduce the heat load. Physiological adaptations increase heat dissipation (i.e., enhanced respiration and sweating rates) and decrease heat production (i.e., reduced feed intake) at the expense of animal performance. Reduced feed intake during heat stress has traditionally been assumed to be primarily responsible for the decrease in milk yield (Collier et al., 1982; West, 2003). However, we have recently demonstrated that lactating heat-stressed (HS) dairy cows exhibit more extensive milk yield reduction per unit of feed intake than pair-fed (PF) thermal neutral counterparts (Rhoads et al., 2009; Wheelock et al., 2010). This result suggests that heat stress-induced changes in feed intake account for $50 \%$ of the overall reduction in milk synthesis. Although both PF and HS cows appear to enter similar levels of negative energy balances, they experience different bioenergetic adaptations (Baumgard and Rhoads, 2013). Contrary to PF controls, HS cows have decreased plasma nonesterified fatty acids (NEFA), 
increased plasma insulin, and increased plasma urea nitrogen, and may increase glucose utilization in peripheral tissues (Rhoads et al., 2009; Wheelock et al., 2010). These adaptations ostensibly indicate a shift in whole-body carbohydrate, lipid, and protein metabolism in heat-stressed cows, independent of reductions in feed intake.

Mammalian metabolic adaptations are coordinated, in part, by the endocrine system to fulfill ever-changing energy demands (Coll et al., 2007). It is well accepted that insulin plays a crucial role in the transition from fasting to fed state. Insulin is the most potent and acute anabolic hormone and it is involved in regulating the turnover of carbohydrates, lipids, and proteins (Saltiel and Kahn, 2001). In relation to carbohydrate metabolism, a unique feature in ruminants is that their circulating glucose originates almost exclusively from hepatic gluconeogenesis because dietary carbohydrates are subjected to microbial fermentation before they become available for absorption in the small intestine (Bell and Bauman, 1997). Insulin suppresses gluconeogenesis by downregulating genes encoding gluconeogenic enzymes (Michael et al., 2000). Hepatic glycogen is another source for plasma glucose and is used as a glucose reservoir. Glycogen accumulation is stimulated by insulin via increasing glucose transport and glycogen synthesis (Saltiel and Kahn, 2001). Basal and stimulated plasma insulin concentrations are typically increased during periods of heat stress in a variety of species (Baumgard and Rhoads, 2013) but how such changes are sensed by the liver; for example, hepatic insulin responsiveness, remain unclear (Rhoads et al., 2013). This is important, because the liver clearly exhibits alterations in gluconeogenic gene expression and growth hormone-dependent IGF-I gene expression during heat stress, possibly related to insulin action (Rhoads et al., 2010, 2011).

Skeletal muscle is a major site of whole-body energy consumption, given its sheer mass, and it has the ability to use different energy substrates based upon nutrient availability. Insulin can play a crucial role in mediating this selectivity shift based on skeletal muscle responsiveness (Long et al., 2011). Negative energy balance is associated with a variety of metabolic changes that are implemented to support the dominant physiological condition of lactation. Marked alterations in carbohydrate metabolism, such as peripheral insulin resistance, ensure partitioning to support the dominant physiological condition of lactation (Bauman and Currie, 1980). Marked alterations in carbohydrate metabolism ensure partitioning of dietary-derived and tissue-originating nutrients toward the mammary gland and away from peripheral tissues such as skeletal muscle. In previous studies, pair-fed thermal neutral cattle initiate adapta- tions, such as increased plasma NEFA and decreased plasma insulin, which appear to preserve glucose for productive functions involving milk synthesis (Rhoads et al., 2009; Wheelock et al., 2010). In contrast, HS dairy cattle do not appear to employ glucose-sparing mechanisms but this has not been directly evaluated in skeletal muscle.

Within the intracellular insulin-signaling pathways, there are several central proteins, including insulin receptor (IR), insulin receptor substrate (IRS), phosphatidylinositol 3-kinase (PI3K), and protein kinase B (PKB or AKT), which function as important junctions of regulation, signal divergence, and crosstalk nodes with other signaling cascades (Taniguchi et al., 2006). The insulin receptor is localized in insulinresponsive tissues at the cell membrane surface to initiate downstream signaling (Karlsson and Zierath, 2007). Activated IR recruits and phosphorylates IRS, which is involved in maintaining glucose homeostasis between fed and fasting statuses (Guo et al., 2009). Via PI3K and a series of second messengers, insulin signaling involves AKT, a kinase that governs physiological functions by up- or downregulating genes related to glycogen synthesis, gluconeogenesis, and lipogenesis and translocation of the glucose transporter GLUT4 (Karlsson and Zierath, 2007).

In the present study, we hypothesized that HS cattle fail to experience whole-body glucose sparing mechanisms to preserve glucose for milk synthesis. To investigate the role of HS on insulin-dependent glucose metabolism, we established a model to examine insulin responsiveness of skeletal muscle and liver during a period of HS or a similar plane of reduced nutrition. An insulin tolerance test (ITT) was used in conjunction with tissue biopsies to measure critical proteins in the insulin-signaling pathway and estimate skeletal muscle and hepatic insulin responsiveness during HS.

\section{MATERIALS AND METHODS}

\section{Animals and Experimental Design}

After acclimating to the environmental chambers (7 d), 12 multiparous lactating Holstein cows (parity = 2; $136 \pm 8$ DIM, $560 \pm 32 \mathrm{~kg}$ of BW) were randomly assigned to 1 of 2 environmental treatments during 2 experimental periods. During period 1, the 2 groups of cows were managed identically and identified as wellfed (WF) if pair-fed (TNPF) in period 2 or as thermal neutral (TN) if heat-stressed (WFHS) in period 2. The total length of the trial was $20 \mathrm{~d}$, with 2 experimental periods (P) consisting of (1) $9 \mathrm{~d}$ of thermal neutral conditions and ad libitum feed intake (TN for group 1, $\mathrm{WF}=$ well-fed for group 2); (2) $9 \mathrm{~d}$ of either heat-stress 
(WFHS, group $1, \mathrm{n}=6$ ) and ad libitum intake or pair fed (TNPF, group $2, \mathrm{n}=6$ ) in thermal neutral conditions. Animals in the thermal neutral control conditions were pair-fed with WFHS animals to eliminate the confounding effects of dissimilar nutrient intake. During $\mathrm{P} 2$, the percentage reduction in feed intake in heatstressed cows was calculated and applied to the feed offered to the TNPF cows. The heat stress environment was designed with cyclical temperatures $\left[31.1-38.9^{\circ} \mathrm{C}\right.$, 20\% humidity: minimum temperature-humidity index $(\mathbf{T H I})=73$, maximum $\mathrm{THI}=80.5]$, attempting to mimic a normal Arizona summer day, with the TNPF animals remaining in a constant environment of $20^{\circ} \mathrm{C}$ $(\mathrm{THI}=64)$. Cows were housed in individual tiestall stanchions at the University of Arizona William J. Parker Agricultural Research Complex (Tucson, AZ). Throughout the experiment, cows were milked twice daily $(0500,1700 \mathrm{~h})$ and milk yields were recorded at each milking. All cows were individually fed a TMR twice daily (0500 and $1700 \mathrm{~h}$ ) and orts were recorded daily before the a.m. feeding. The TMR was formulated by Chandler Analytical Laboratories (Chandler, AZ) to meet or exceed the predicted requirements (NRC, 2001) of energy, protein, minerals, and vitamins (Table 1). Alfalfa hay was the primary forage, with steamflaked corn as the primary concentrate. The TMR was sampled weekly and analyzed by wet chemistry methods (Chandler Analytical Laboratories). Milk samples from each cow (from both the morning and evening milking) were collected on d 1, 3, 6 and 9 of each period and stored at $4^{\circ} \mathrm{C}$ with a preservative (bronopol tablet; D\&F Control System, San Ramon, CA) until analysis by Arizona DHIA (Tempe, AZ) using AOAC International (2000)-approved infrared analysis equipment and procedures for milk components. Rectal temperature (Tre) and respiration rate (RR) were measured thrice daily at 0430, 1200, and $1630 \mathrm{~h}$. Rectal temperatures were measured using a standard digital thermometer (GLA M700 Digital Thermometer, San Luis Obispo, CA). Respiration rates were determined by counting flank movements for $60 \mathrm{~s}$. All procedures were approved by the University of Arizona Institutional Animal Care and Use Committee.

\section{Net Energy Balance Analysis}

Body weights were obtained on all animals on d 1 , 4 , and 9 of each period and were used to calculate net energy balance (EBAL) using the following equation: $\mathrm{EBAL}=$ net energy intake $-\left(\mathrm{NE}_{\mathrm{M}}+\mathrm{NE}_{\mathrm{L}}\right)$. Maintenance energy requirement was calculated using the equation: $\mathrm{NE}_{\mathrm{M}}=\left(0.08 \times \mathrm{BW}^{0.75} ; \mathrm{NRC}, 2001\right)$ and was increased by $25 \%$ during the HS conditions as recom- mended (NRC, 1989). Net energy for lactation was calculated as follows: $\mathrm{NE}_{\mathrm{L}}=[(0.0929 \times$ fat $\%)+(0.0547$ $\times \mathrm{CP} \%)+(0.0395 \times$ lactose $\%)] \times$ milk yield $(\mathrm{NRC}$, 2001).

\section{Blood Sampling and ITT}

Bilateral indwelling jugular catheters were inserted in all cows on d 4 of each period. On d 9 of each period, an ITT $(1 \mu \mathrm{g} / \mathrm{kg}$ of BW) was administered at $1400 \mathrm{~h}$, as performed previously (O'Brien et al., 2010). Bovine insulin (Sigma, St. Louis, MO) was initially dissolved to $1 \mathrm{mg} / \mathrm{mL}$ in $0.1 \mathrm{M} \mathrm{HCl}$ and then diluted into sterile saline and kept at $-80^{\circ} \mathrm{C}$ until use. After insulin i.v. infusion, the catheter was flushed with $12 \mathrm{~mL}$ of sterile saline. Blood samples were collected at $-30,7.5,15,30$, and $60 \mathrm{~min}$ relative to insulin infusion. Samples were collected into disposable glass tubes containing $250 \mathrm{U}$ of sodium heparin and were immediately placed on ice. After centrifugation, plasma was split into 2 aliquots and stored at $-20^{\circ} \mathrm{C}$; one aliquot was later analyzed for plasma glucose concentration and the other for insulin concentration.

Plasma glucose and insulin concentrations were determined with commercially available kits (Autokit Glucose C2; Wako Chemicals USA, Richmond, VA; and Mercodia Bovine Insulin ELISA, ALPCO Diagnostics, Salem, NH) as previously described (O'Brien et al.,

Table 1. Ingredients and chemical composition (\% of DM unless noted) of diets

\begin{tabular}{lc}
\hline Item & Content \\
\hline Ingredient & \\
Alfalfa hay & 50.3 \\
Steam-flaked corn & 25.5 \\
Whole cottonseed $^{1}$ & 8.7 \\
Amino plus & 2.1 \\
Beet pulp & 4.8 \\
Molasses & 4.3 \\
Supplement & \\
Calcium salts of palm oil & 3 \\
Chemical analysis & 2.4 \\
Moisture & 1.9 \\
Ash & \\
NDF & 8.5 \\
ADF & 13.4 \\
CP & 32.8 \\
\end{tabular}

${ }^{1}$ Soybean-based supplement; 51.7\% CP (Ag Processing Inc., Hasting, $\mathrm{NE}$ ).

${ }^{2}$ Contained $1.34 \%$ fat, $6.23 \%$ Ca, $4.49 \%$ P, $3.10 \% \mathrm{Mg}, 0.58 \% \mathrm{~S}, 0.23 \%$ $\mathrm{K}, 16.18 \% \mathrm{Na}, 3.7 \% \mathrm{Cl}, 2,290.59 \mathrm{mg} / \mathrm{kg}$ of $\mathrm{Zn}, 2,037.94 \mathrm{mg} / \mathrm{kg}$ of Mn, $1,109.46 \mathrm{mg} / \mathrm{kg}$ of Fe, $629.18 \mathrm{mg} / \mathrm{kg}$ of $\mathrm{Cu}, 75.02 \mathrm{mg} / \mathrm{kg}$ of Co, 13.83 $\mathrm{mg} / \mathrm{kg}$ of Se, $10.40 \mathrm{mg} / \mathrm{kg}$ of Mo, $51.65 \mathrm{mg} / \mathrm{kg}$ of I, $360.16 \mathrm{IU} / \mathrm{g}$ of vitamin $\mathrm{A}, 35.67 \mathrm{IU} / \mathrm{g}$ vitamin $\mathrm{D}$, and $1.16 \mathrm{IU} / \mathrm{g}$ of vitamin $\mathrm{E}$.

${ }^{3}$ Maxxer (Tarome Inc., Eloy, AZ). 
2010). The intra- and interassay coefficients of variation were 3.5 and $3.3 \%$ for glucose and 7.1 and $6.6 \%$ for insulin, respectively.

\section{Western Immunoblot Analysis}

To evaluate skeletal muscle and liver insulin responsiveness, biopsies were obtained immediately before $(-15 \mathrm{~min})$ and after $(+15 \mathrm{~min})$ the ITT. These time points were chosen because investigations into proximal in vivo signaling rely on rapid tissue sampling $<15 \mathrm{~min}$ after hormone administration to accurately assess cellular activation (Dominici et al., 1999; Morisco et al., 2000; Rhoads et al., 2010). Skeletal muscle biopsy sites were shaved and aseptically cleaned with betadine and $70 \%$ isopropanol. The first biopsy was obtained at -15 min relative to the ITT. Five minutes before the first biopsy, $10 \mathrm{~mL}$ of $2 \%$ lidocaine (MWI Veterinary Supply Co., Glendale, AZ) was administered in an umbrellalike fashion to the biopsy site of the right hindlimb. An incision approximately $5 \mathrm{~cm}$ in length was made in the right hindlimb semitendinosus. A sterile biopsy punch ( $8 \mathrm{~mm}$, Miltex Inc., York, PA) was used to collect one tissue core from the semitendinosus muscle. At $15 \mathrm{~min}$ post-insulin injection, a second muscle biopsy was obtained on the semitendinosus of the left hindlimb following the preparation and collection protocol as described above. Following tissue sample collection, incision sites were sutured (Ethicon, MWI Veterinary Supply Co.), cleaned with $70 \%$ isopropanol, and disinfected with an aerosol bandage (Allushield, Valley Vet, Maryville, KS). Liver samples were collected by percutaneous needle biopsy as described previously (Rhoads et al., 2007). Biopsies were snap-frozen in liquid nitrogen and kept at $-80^{\circ} \mathrm{C}$ until molecular analyses. Total protein extracts were prepared as described previously (Rhoads et al., 2010). Protein content of extracts was measured with the bicinchoninic acid protein assay (Pierce, Rockford, IL). Protein abundance of IR, IRS, AKT, and phosphorylated AKT (p-AKT) were measured by Western blot analyses as previously described (Rhoads et al., 2010). Antibodies were rabbit anti-mouse AKT, rabbit anti-human p-AKT Ser 473 (Cell Signaling Technology Inc., Danvers, MA), rabbit anti-human IR and rabbit anti-human IRS (Santa Cruz Biotechnology Inc., Santa Cruz, CA), and rabbit anti-human $\alpha$-tubulin (Cell Signaling Technology Inc.). Antibody specificity was tested in competition experiments with the blocking peptide for each antibody. Signals were detected by chemiluminescence (LumiGLO, KPL, Gaithersburg, MD) and quantified by densitometry using the National Institutes of Health Image J software (http://imagej. nih.gov/ij/).

\section{Statistical Analysis}

The plasma glucose response to insulin was calculated as area under the curve (AUC) by use of linear trapezoidal summation between successive pairs of glucose concentrations and time coordinates after correcting for the baseline concentration (Baumgard et al., 2002). Baseline concentrations were defined as the samples at -30 min before insulin infusion.

Protein and plasma glucose data were analyzed with the Proc Glimmix procedure (SAS Institute, Cary, NC) accounting for treatment (TN vs. WFHS or WF vs. TNPF) as a fixed effect and animal as the random effect. For Tre, RR, and plasma insulin, each cow was analyzed using repeated measures with an autoregressive covariance structure and time as the repeated effect. The model contained covariate, treatment, time, and a treatment $\times$ time interaction. Data are reported as least-squares means (LSM) and considered significant if $P<0.05$ or a trend if $0.05<P<0.1$.

Table 2. Effects of heat stress (HS) or pair-feeding (PF) on rectal temperature (Tre) and respiration rate (RR; breaths/min, bpm) in lactating Holstein cows ${ }^{1}$

\begin{tabular}{|c|c|c|c|c|c|c|c|c|}
\hline \multirow[b]{2}{*}{ Variable/time } & \multicolumn{2}{|c|}{ Period 1} & \multicolumn{2}{|c|}{ Period 2} & \multirow[b]{2}{*}{ SEM } & \multicolumn{3}{|c|}{$P$-value ${ }^{2}$} \\
\hline & Group $1(\mathrm{TN})$ & Group 2 (WF) & Group 1 (WFHS) & Group 2 (TNPF) & & TRT & PER & $\mathrm{TRT} \times \mathrm{PER}$ \\
\hline $0430 \mathrm{~h}$ & $38.23^{\mathrm{a}}$ & $38.25^{\mathrm{a}}$ & $39.17^{\mathrm{c}}$ & $38.55^{\mathrm{b}}$ & 0.07 & $<0.01$ & $<0.01$ & $<0.01$ \\
\hline $1200 \mathrm{~h}$ & $38.26^{\mathrm{a}}$ & $38.22^{\mathrm{a}}$ & $39.65^{\mathrm{b}}$ & $38.29^{\mathrm{a}}$ & 0.08 & $<0.01$ & $<0.01$ & $<0.01$ \\
\hline $1630 \mathrm{~h}$ & $38.30^{\mathrm{a}}$ & $38.33^{\mathrm{a}}$ & $40.14^{\mathrm{c}}$ & $38.66^{\mathrm{b}}$ & 0.06 & $<0.01$ & $<0.01$ & $<0.01$ \\
\hline \multicolumn{9}{|l|}{ RR (bpm) } \\
\hline $1630 \mathrm{~h}$ & $36^{\mathrm{a}}$ & $39^{\mathrm{a}}$ & $83^{\mathrm{b}}$ & $35^{\mathrm{a}}$ & 2 & $<0.01$ & $<0.01$ & $<0.01$ \\
\hline
\end{tabular}

\footnotetext{
${ }^{\mathrm{a} c}$ Values within a row of each variable with differing superscripts indicate statistical difference $(P<0.05)$.

${ }^{1}$ During period 1, cows in both groups were treated identically [housed in thermal neutral (TN) conditions and fed ad libitum (WF)]. During period 2, cows were either heat-stressed and fed ad libitum (WFHS) or kept in TN conditions and pair-fed (TNPF).

${ }^{2} \mathrm{TRT}=$ treatment $\mathrm{PER}=$ period; TRT $\times \mathrm{PER}=$ treatment $\times$ period interaction.
} 


\section{RESULTS}

We detected no TN or WF differences in Tre or RR during P1 (Table 2). Cows from WFHS conditions during $\mathrm{P} 2$ exhibited increased $(P<0.05)$ Tre and RR compared with TNPF during P2. During P2, TNPF animals had increased $(P<0.05)$ Tre compared with that in $\mathrm{P} 1$ at 0430 and $1630 \mathrm{~h}$, but these differences $\left(0.22\right.$ and $\left.0.36^{\circ} \mathrm{C}\right)$ were relatively small compared with those of WFHS.

Feed intake of TN cows decreased $(P<0.01)$ in $\mathrm{P} 2$ during WFHS conditions (Figure 1A). Heat stress progressively decreased DMI until d 5 and DMI remained similarly depressed from d 5 to 9 . Feed intake of TNPF mirrored the decreasing pattern of WFHS feed intake. Cows during TNPF had lower overall DMI $(P<0.01)$
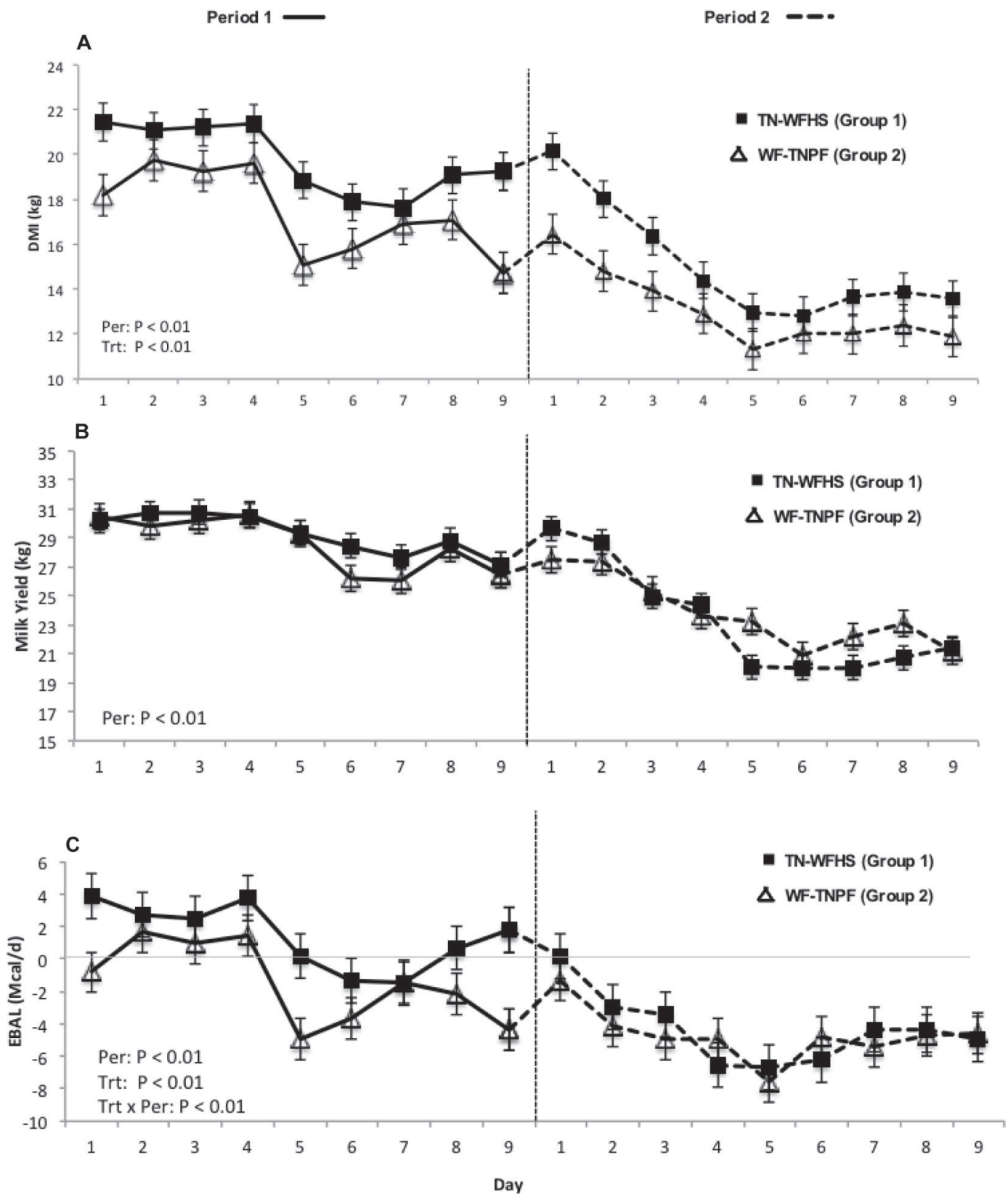

Figure 1. Effects of heat stress or pair-feeding on (A) DMI, (B) milk yield, and (C) energy balance (EBAL) in lactating Holstein cows. Dairy cattle were maintained in constant thermal neutral conditions and fed ad libitum for $9 \mathrm{~d}$ (TN and WF) followed by exposure to cyclical temperatures ranging from 29.4 to $38.9^{\circ} \mathrm{C}$ with constant $20 \%$ humidity and were fed ad libitum (WFHS) or exposed to constant thermal neutral conditions and pair-fed (TNPF) with HS counterparts. Squares represent TN-WFHS cows and triangles represent WF-TNPF cows. Per $=$ period; Trt = treatment. Error bars represent SEM. 
Table 3. Effects of heat stress (HS) or pair-feeding (PF) on milk composition in lactating Holstein cows ${ }^{1}$

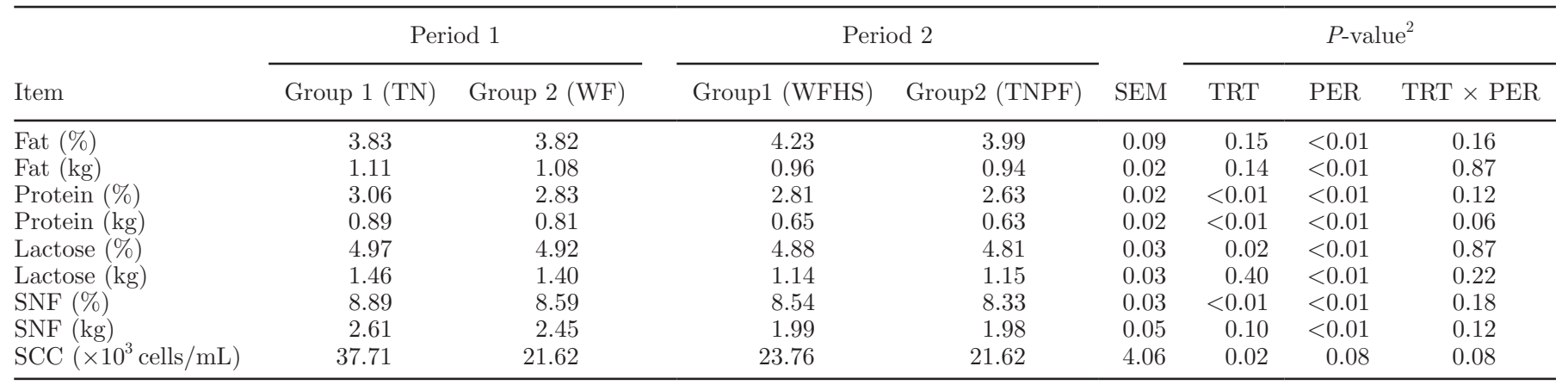

${ }^{1}$ During period 1, cows in both groups were treated identically [housed in thermal neutral (TN) conditions and fed ad libitum (WF)]. During period 2, cows were either heat-stressed and fed ad libitum (WFHS) or kept in TN conditions and pair-fed (TNPF).

${ }^{2} \mathrm{TRT}=$ treatment $\mathrm{PER}=$ period; TRT $\times \mathrm{PER}=$ treatment $\times$ period interaction.

compared with those in WFHS. This difference existed in P1 and, by design, remained in P2. We observed no group difference in milk yield in either P1 or P2 (Figure 1B). Both groups progressively decreased milk production after initiation of P2. Compared with $\mathrm{P} 1$, milk fat content was higher $(P<0.01)$ but milk fat yield was lower $(P<0.01)$ during P2 for both groups (Table 3 ). There tended to be a treatment $\times$ period interaction on milk protein content $(P=0.12)$ and yield $(P=0.06)$ as the decrease was more severe (compared with TNPF cows) for both variables in WFHS cows (Table 3). Overall, TNPF cows had a higher milk lactose content than WFHS cows but this difference $(0.16 \%)$ existed in P1 and continued during P2 (Table 3). During P2, milk SNF content and yield was lower $(P<0.01)$ for both WFHS and TNPF cows, but TNPF cows had overall greater $(P<0.01)$ milk SNF content (Table 3$)$. There tended to be a treatment $\times$ period interaction $(P<$ 0.08 ) on milk SCC as it did not differ from P1 to P2 in TNPF cows but decreased during P2 for WFHS cows (Table 3).
Overall, EBAL was lower $(P<0.01)$ in TNPF compared with WFHS and in P2 compared with P1 (Figure $1 \mathrm{C})$. We detected a treatment $\times$ period interaction indicating that the extent of decrease in EBAL was different between groups. Both groups were in negative EBAL (NEBAL) condition during P2, and the severity of NEBAL continued to progress for the first $5 \mathrm{~d}$ in P2 and stabilized for the rest of P2.

We observed a tendency $(P=0.10)$ for a treatment $\times$ period interaction for basal plasma glucose levels, where concentration decreased during P2 for WFHS cows (Table 4). The ITT caused a less rapid glucose disposal in $\mathrm{P} 2$ compared with $\mathrm{P} 1(P<0.05)$, as indicated by greater absolute values (areas under the curve) at 30 and 60 min in P1 versus P2, but glucose clearance did not differ between groups in P2 (Table 4; Figure 2). Basal plasma insulin concentration and the glucose:insulin ratio were not altered by treatment or period (Table 4).

In muscle, protein abundance of IR, IRS, and AKT remained stable between periods and environments

Table 4. Effects of heat stress (HS) or pair-feeding (PF) on glucose and insulin responses to an insulin tolerance test in lactating Holstein cows ${ }^{1}$

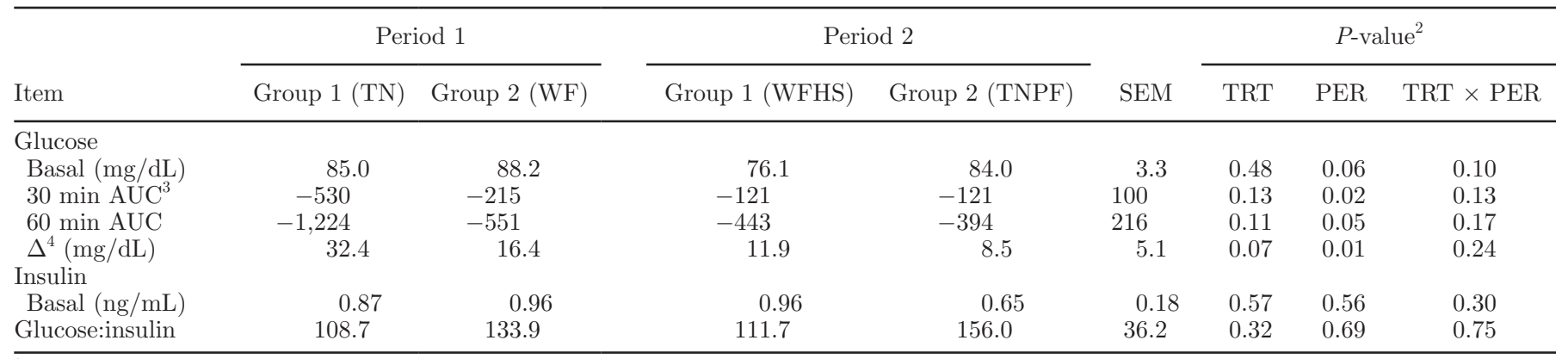

${ }^{1}$ During period 1, cows in both groups were treated identically [housed in thermal neutral (TN) conditions and fed ad libitum (WF)]. During period 2, cows were either heat-stressed and fed ad libitum (WFHS) or kept in TN conditions and pair-fed (TNPF).

${ }^{2} \mathrm{TRT}=$ treatment; PER $=$ period; TRT $\times$ PER $=$ treatment $\times$ period interaction.

${ }^{3}$ Area under the curve $(\mathrm{mg} \cdot \mathrm{dL} \cdot \mathrm{min})$.

${ }^{4}$ Change in glucose concentrations between the start of insulin infusion and glucose response nadir. 
(Figure 3A and B). Insulin increased p-AKT protein abundance in each period $(P<0.05)$, but this response tended to decline in P2 for TNPF animals $(P=0.09)$, but not for WFHS (Figure 3A and B). After insulin infusion, the phosphorylation ratio (abundance of phosphorylated protein:abundance of total protein) of AKT was decreased $(P<0.05)$ by TNPF treatment (Figure $3 \mathrm{D})$, whereas it remained unchanged in WFHS cows (Figure 3C).

In the liver, insulin increased p-AKT protein content and phosphorylation ratio of AKT in each period $(P<$ 0.05 ) but they did not differ between periods (Figure $4 \mathrm{C}$ and D). Protein abundances of IR and IRS remained constant during each period and were not altered by insulin challenge (Figure 4A and $\mathrm{B}$ ).

\section{DISCUSSION}

Reduced feed intake was traditionally thought to be the major cause of milk yield decrease in dairy cows exposed to an environmental heat load above their thermal comfort zone. Using experiments designed to separate confounding effects of high temperature and nutritional deficiency, we have reported that reduced feed intake can explain only part of the milk yield reduction in dairy cows under HS conditions (Rhoads et al., 2009; Wheelock et al., 2010). In the present study, a greater amount of feed was consumed to maintain similar levels of milk production between WFHS and TNPF during P2 despite the same percentage decline in feed intake between the 2 groups. Overall, this is consistent with the observation that HS, independent of reduced feed intake, directly contributes to milk yield decline.

It is well documented that malnourished lactating animals reduce plasma insulin or sensitivity (or both) as a homeorhetic mechanism to spare glucose for the mammary gland (Bauman and Currie, 1980; Escrivá et al., 1992; Kemnitz et al., 1994; Bauman, 1999; Davis et al., 2010). During P2, both WFHS and TNPF cows reduced their glucose clearance rate during an ITT compared with P1, but there was no treatment difference. Reduced feed intake appeared to sufficiently explain the lowered systemic insulin sensitivity observed in $\mathrm{P} 2$ in terms of the glucose disposal rate. However, at the molecular level, insulin signaling in skeletal muscle and liver were maintained in the WFHS group, whereas the TNPF group decreased insulin signaling in skeletal muscle. If blunted insulin sensitivity and glucose clearance stems from decreased skeletal muscle AKT phosphorylation in the TNPF animals, insulin resistance in WFHS appears to occur downstream of the AKT phosphorylation event. In a previous study with a similar experimental design, Wheelock et al.
(2010) demonstrated that TNPF animals decreased insulin secretion during a glucose tolerance test (GTT), whereas WFHS animals did not. Other heat-stressed animal studies reported increased secretion of insulin during GTT in cattle (Itoh et al., 1998), augmented basal insulin level in mice (Morera et al., 2012), and increased whole-body insulin-stimulated glucose uptake in pigs (Sanz Fernandez et al., 2015) under hyperthermic conditions. Overall, despite a marked decline in feed intake, heat-stressed animals maintained or even increased insulin secretion while the glucose disappearance rate was significantly suppressed. There are several possible explanations: (1) elevated intracellular $\mathrm{Ca}^{2+}$ is reported in malignant hyperthermia susceptible humans and elevated $\mathrm{Ca}^{2+}$ suppresses insulin-mediated glucose uptake in skeletal muscle (Freymond et al., 2000); (2) plasma glucose is compensated by increased hepatic glucose output during HS from gluconeogenesis (O'Brien et al., 2010; Rhoads et al., 2011; White et al., 2012) or glycogenolysis (Febbraio, 2001) and these events become refractory to insulin during HS; (3) unknown post-receptor signaling alterations occur downstream of IR in skeletal muscle, leading to reduced glucose uptake. In addition, insulin-mediated glucose

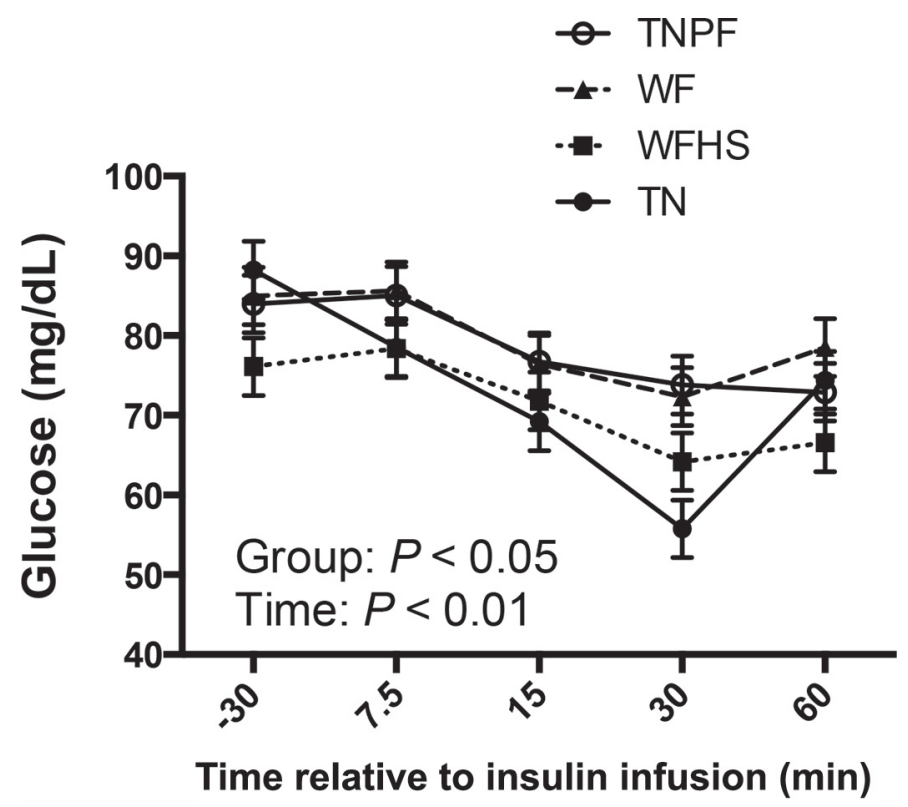

Figure 2. Effects of heat stress or pair-feeding on glucose disposal rate during an insulin challenge (ITT) in lactating Holstein cows. Dairy cattle were maintained in constant thermal neutral conditions and fed ad libitum for $9 \mathrm{~d}$ (TN and WF) followed by exposure to cyclical temperatures ranging from 29.4 to $38.9^{\circ} \mathrm{C}$ with constant $20 \%$ humidity and were fed ad libitum (WFHS) or exposed to constant thermal neutral conditions and pair-fed (TNPF) with HS counterparts. On d 6 of each period, insulin was administered via jugular catheter and blood samples were collected at $-30,7.5,15,30$, and 60 min relative to insulin administration. 
uptake is not the only approach enlisted by animals to regulate glucose flux. Insulin-independent glucose transporters are expressed in a tissue-specific manner (Zhao and Keating, 2007) and HS may affect different routes of glucose fluxes.

The mechanism(s) by which HS may alter insulin sensitivity is unknown. Evidence indicates that hyperthermia may lessen the development of insulin-resistance via heat stress proteins (HSP), which either protects pancreatic $\beta$-cells (Kondo et al., 2012) or counteracts stress kinases, which contribute to insulin-resistance, in skeletal muscle (Geiger and Gupte, 2011). Hooper and Hooper (2009) proposed a self-perpetuating cycle model for the relationship between insulin and HSP: (1) obesity-driven inflammation triggers insulin resistance; (2) impaired insulin signaling in turn reduces the expression of HSP, subsequently leading to vulner- able pancreas tissue and accumulation of inflammatory cytokines and their related proteins; and (3) damaged pancreas $\beta$-cells further lower insulin signaling, and the lack of anti-inflammatory HSP allows inflammation to expand unhindered. Together, it is reasonable to speculate that heat stress could maintain insulin signaling and stimulate insulin secretion in lactating cows during NEBAL by upregulating expression of HSP.

The insulin-sensitive glucose transporter isoform GLUT4 is primarily expressed in skeletal muscle and adipose tissue. The redistribution of GLUT4 vesicles from the cytoplasm to the plasma membrane triggered by insulin is responsible for a net 10- to 40-fold increase in glucose influx into the cells and the PI3K-AKT pathway plays an important role in GLUT4 translocation (Whiteman et al., 2002). Phosphorylation at residues Thr308 and Ser473 of AKT is necessary for the induc-

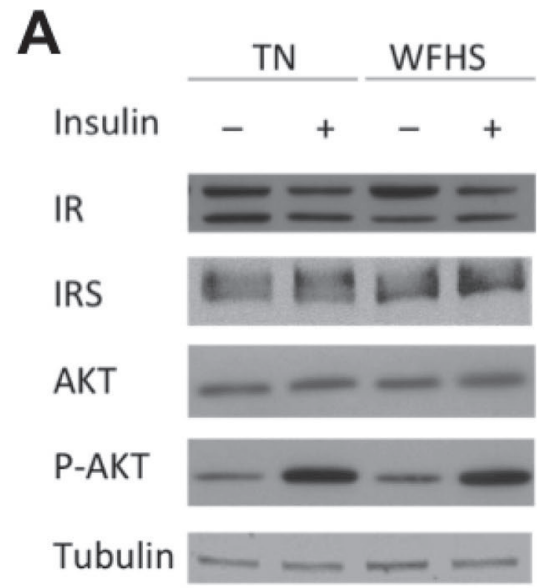

C

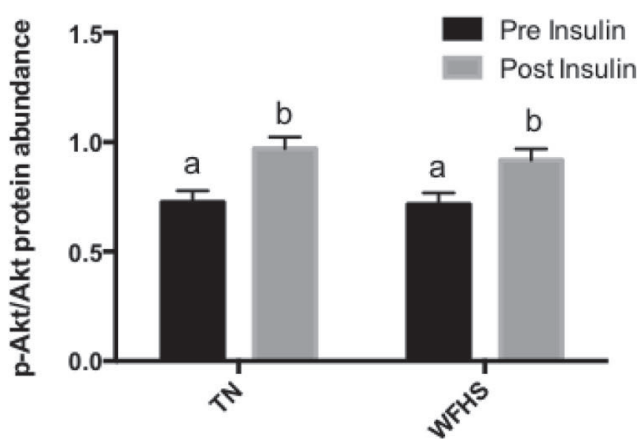

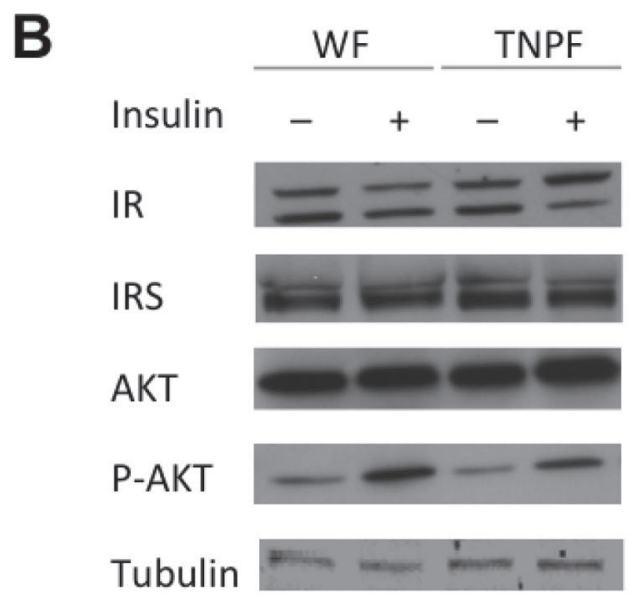

D

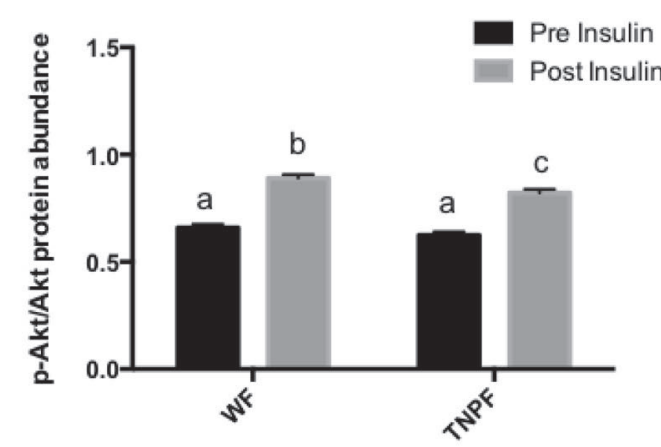

Figure 3. Effect of heat stress and insulin challenge on skeletal muscle components of insulin signaling. Dairy cattle were maintained in constant thermal neutral conditions and fed ad libitum for $9 \mathrm{~d}$ (TN and WF) followed by exposure to cyclical temperatures ranging from 29.4 to $38.9^{\circ} \mathrm{C}$ with constant $20 \%$ humidity and were fed ad libitum (WFHS) or exposed to constant thermal neutral conditions and pair-fed (TNPF) with HS counterparts. On d 6 of each period, insulin was administered with skeletal muscle biopsies obtained at -15 (Pre) and 15 min (Post) relative to insulin administration. (A and B) Muscle protein extracts were analyzed by western immunoblotting for the abundance of the insulin receptor (IR), insulin receptor substrate (IRS), AKT and phosphorylated AKT (p-AKT). Data are from one representative cow. (C and D) Bars represent means $\pm \mathrm{SE}$ of AKT protein phosphorylation ratio (abundance of p-AKT:abundance of AKT). Bars with different letters differ at $P<0.05$. 
tion of GLUT4 vesicle exocytosis (Watson and Pessin, 2006). In the current study, the phosphorylation ratio of AKT in skeletal muscle was reduced by TNPF but not by WFHS, indicating that nutrient deprivation decreased AKT activation level, whereas direct effects of high ambient temperature were sufficient for maintenance of AKT activation. A possible explanation for the reduction in AKT phosphorylation observed in TNPF cows may be mediated by AMP-activated protein kinase (AMPK) energy sensing system. As an energy sensor, AMPK reacts to fluctuations in the ratio ATP:AMP as well as phosphocreatine:creatine (Winder, 2001) and is able to attenuate the phosphorylation of AKT at Ser473 (Bolster et al., 2002). In contrast, heat-stress conditions may dephosphorylate AMPK $\alpha$, the catalytic subunit of AMPK, and therefore inhibit the physiological functions of AMPK (Wang et al., 2010). Both WFHS and TNPF animals maintained the AKT phosphorylation ratio in liver at the same level as in the TN and WF periods, respectively. Together, these results indicate that heat stress may prevent cows from sparing glucose for milk synthesis by maintaining the AKT phosphorylation ratio in skeletal muscle. How AKT activation remains unchanged in skeletal muscle during heat stress is unclear and warrants further studies on the relationship between heat stress and AMPK signaling that may shed some light the underlying mechanisms.
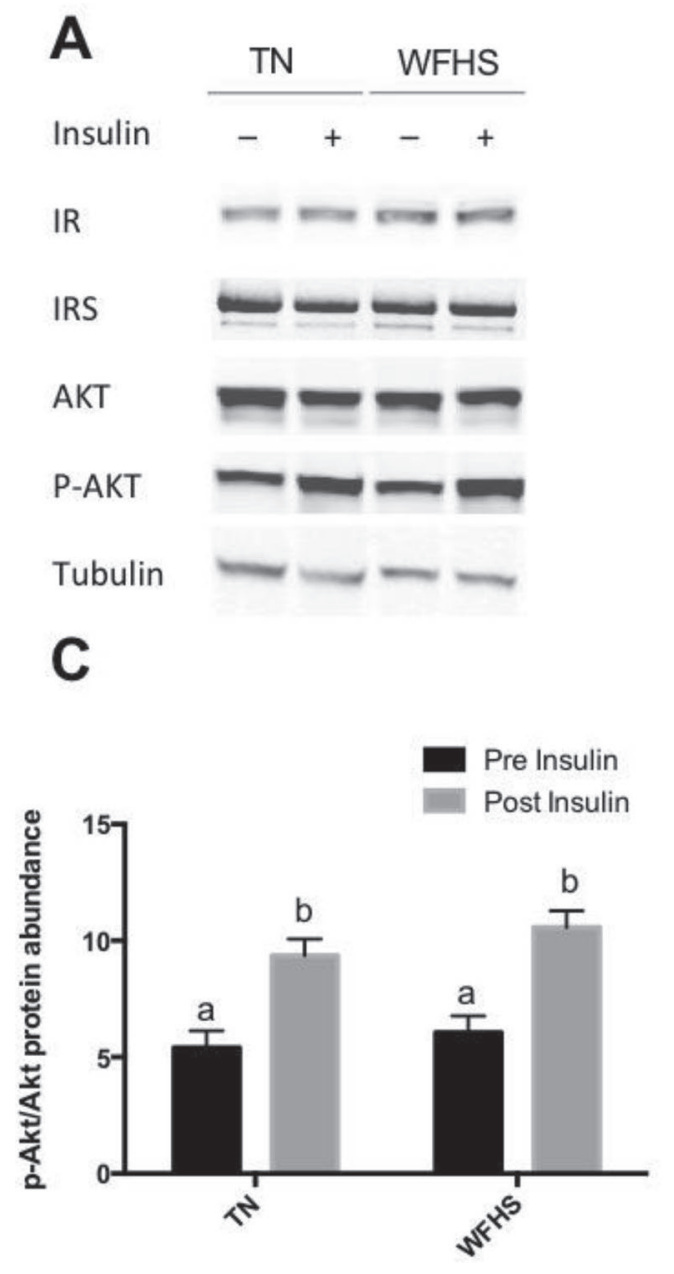

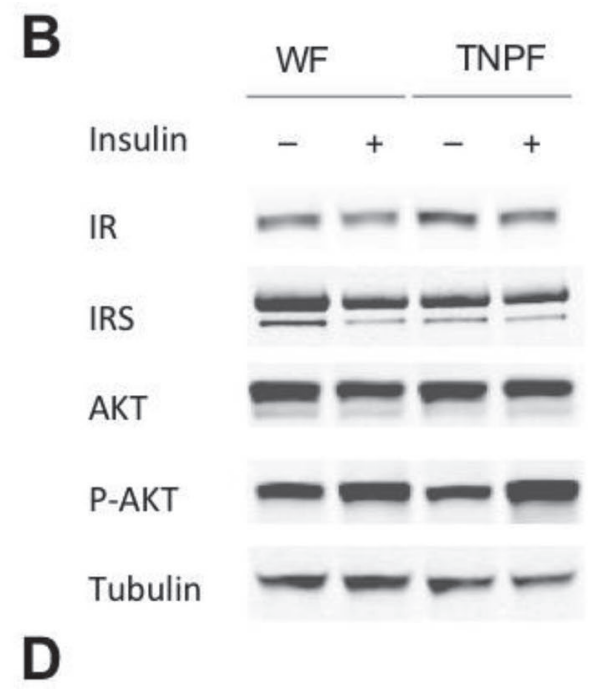

Pre Insulin

Post Insulin

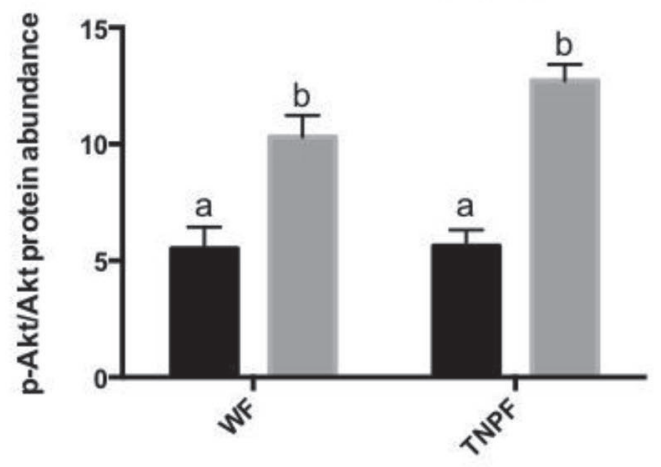

Figure 4. Effect of heat stress and insulin challenge on liver components of insulin signaling. Dairy cattle were maintained in constant thermal neutral conditions and fed ad libitum for $9 \mathrm{~d}$ ( TN and $\mathrm{WF}$ ) followed by exposure to cyclical temperatures ranging from 29.4 to $38.9^{\circ} \mathrm{C}$ with constant $20 \%$ humidity and were fed ad libitum (WFHS) or exposed to constant thermal neutral conditions and pair-fed (TNPF) with HS counterparts. On d 6 of each period, insulin was administered with liver biopsies obtained at - 15 (Pre) and 15 min (Post) relative to insulin administration. (A and B) Liver protein extracts were analyzed by western immunoblotting for the abundance of the insulin receptor (IR), insulin receptor substrate 1 (IRS-1), AKT and phosphorylated AKT (p-AKT). Data are from one representative cow. (C and D) Phosphorylation ratio of AKT comparisons between periods; bars represent means \pm SE of AKT protein phosphorylation ratio (abundance of p-AKT:abundance of AKT). Bars with different letters differ at $P<0.05$. 


\section{CONCLUSIONS}

We previously demonstrated that decreased feed intake explains only about $50 \%$ of the decline in milk production during heat stress in dairy cows and that hyperthermic conditions directly lower milk yield via other mechanisms. In the present study, we focused on measuring systemic insulin response because insulin signaling occupies a central role in orchestrating wholebody glucose metabolism. Both pair-feeding and heat stress reduced whole-body insulin sensitivity in terms of glucose disposal. Insulin-activated downstream signaling performed equally well in skeletal muscle and liver during thermal neutral and heat stress periods but insulin signaling via AKT was blunted only during the pair-fed period in muscle. The mechanism of shunting glucose into milk production used by pair-fed animals may be mediated by reducing insulin post-receptor signaling, whereas heat-stressed cows did not appear to use this mechanism. Future experiments are needed to investigate the signaling pathways underlying the maintained tissue insulin sensitivity despite an overall reduction in systemic insulin sensitivity during heat stress. In addition, the role that other tissues, such as adipose, play in insulin sensitivity and glucose homeostasis during heat stress warrants further attention.

\section{ACKNOWLEDGMENTS}

Funding for this work was provided, in part, by the University of Arizona Experiment Station (Tucson; \#ARZT-136339-H-24-130), by the Virginia Agricultural Experiment Station (Blacksburg) and the Hatch Program of the National Institute of Food and Agriculture, US Department of Agriculture, and National Research Initiative Competitive Grants no. 2008-3520618817 and 2010-65206-20206 from the USDA National Institute of Food and Agriculture (Washington, DC).

\section{REFERENCES}

AOAC International. 2000. Official Methods of Analysis. 17th ed. AOAC International, Washington, DC.

Bauman, D. E. 1999. Bovine somatotropin and lactation: From basic science to commercial application. Domest. Anim. Endocrinol. 17:101-116.

Bauman, D. E., and W. B. Currie. 1980. Partitioning of nutrients during pregnancy and lactation: A review of mechanisms involving homeostasis and homeorhesis. J. Dairy Sci. 63:1514-1529.

Baumgard, L. H., and R. P. Rhoads. 2013. Effects of heat stress on postabsorptive metabolism and energetics. Annu. Rev. Anim. Biosci. 1:311-337. http://dx.doi.org/10.1146/annurevanimal-031412-103644.

Baumgard, L. H., W. J. Weber, H. Chester-Jones, L. B. Hansen, G. W. Kazmer, S. A. Zinn, and B. A. Crooker. 2002. Growth hormone response to growth hormone releasing factor by Holstein calves from genetic lines selected for milk yield. J. Dairy Sci. 85:2529-2540.
Bell, A. W., and D. E. Bauman. 1997. Adaptations of glucose metabolism during pregnancy and lactation. J. Mammary Gland Biol. Neoplasia 2:265-278.

Bolster, D. R., S. J. Crozier, S. R. Kimball, and L. S. Jefferson. 2002. AMP-activated protein kinase suppresses protein synthesis in rat skeletal muscle through down-regulated mammalian target of rapamycin (mTOR) signaling. J. Biol. Chem. 277:23977-23980.

Coll, A. P., I. S. Farooqi, and S. O'Rahilly. 2007. The hormonal control of food intake. Cell 129:251-262.

Collier, R. J., D. K. Beede, W. W. Thatcher, L. A. Israel, and C. J. Wilcox. 1982. Influences of environment and its modification on dairy animal health and production. J. Dairy Sci. 65:2213-2227.

Davis, J. F., D. L. Choi, and S. C. Benoit. 2010. Insulin, leptin and reward. Trends Endocrinol. Metab. 21:68-74.

Dominici, F. P., D. Cifone, A. Bartke, and D. Turyn. 1999. Alterations in the early steps of the insulin-signaling system in skeletal muscle of GH-transgenic mice. Am. J. Physiol. 277:E447-E454.

Escrivá, F., C. Rodriguez, J. Cacho, C. Alvarez, B. Portha, and A. M. Pascual-Leone. 1992. Glucose utilization and insulin action in adult rats submitted to prolonged food restriction. Am. J. Physiol. 263:E1-E7.

Febbraio, M. A. 2001. Alterations in energy metabolism during exercise and heat stress. Sports Med. 31:47-59.

Freymond, D., O. Deriaz, P. Frascarolo, S. Reiz, E. Jequier, and A. Urwyler. 2000. In vivo whole-body resting energy expenditure and insulin action in human malignant hyperthermia. Anesthesiology 93:39-47.

Geiger, P. C., and A. A. Gupte. 2011. Heat shock proteins are important mediators of skeletal muscle insulin sensitivity. Exerc. Sport Sci. Rev. 39:34-42.

Guo, S., K. D. Copps, X. Dong, S. Park, Z. Cheng, A. Pocai, L. Rossetti, M. Sajan, R. V. Farese, and M. F. White. 2009. The Irs1 branch of the insulin signaling cascade plays a dominant role in hepatic nutrient homeostasis. Mol. Cell. Biol. 29:5070-5083.

Hooper, P. L., and P. L. Hooper. 2009. Inflammation, heat shock proteins, and type 2 diabetes. Cell Stress Chaperones 14:113-115.

Itoh, F., Y. Obara, M. T. Rose, H. Fuse, and H. Hashimoto. 1998. Insulin and glucagon secretion in lactating cows during heat exposure. J. Anim. Sci. 76:2182-2189.

Karlsson, H. K., and J. R. Zierath. 2007. Insulin signaling and glucose transport in insulin resistant human skeletal muscle. Cell Biochem. Biophys. 48:103-113.

Kemnitz, J. W., E. B. Roecker, R. Weindruch, D. F. Elson, S. T. Baum, and R. N. Bergman. 1994. Dietary restriction increases insulin sensitivity and lowers blood glucose in rhesus monkeys. Am. J. Physiol. 266:E540-E547.

Kondo, T., K. Sasaki, R. Matsuyama, S. Morino-Koga, H. Adachi, M. A. Suico, J. Kawashima, H. Motoshima, N. Furukawa, H. Kai, and E. Araki. 2012. Hyperthermia with mild electrical stimulation protects pancreatic beta-cells from cell stresses and apoptosis. Diabetes 61:838-847.

Long, Y. C., Z. Cheng, K. D. Copps, and M. F. White. 2011. Insulin receptor substrates Irs1 and Irs2 coordinate skeletal muscle growth and metabolism via the Akt and AMPK pathways. Mol. Cell. Biol. 31:430-441.

Michael, M. D., R. N. Kulkarni, C. Postic, S. F. Previs, G. I. Shulman, M. A. Magnuson, and C. R. Kahn. 2000. Loss of insulin signaling in hepatocytes leads to severe insulin resistance and progressive hepatic dysfunction. Mol. Cell 6:87-97.

Morera, P., L. Basirico, K. Hosoda, and U. Bernabucci. 2012. Chronic heat stress up-regulates leptin and adiponectin secretion and expression and improves leptin, adiponectin and insulin sensitivity in mice. J. Mol. Endocrinol. 48:129-138.

Morisco, C., G. Condorelli, F. Orzi, G. Vigliotta, R. Di Grezia, F. Beguinot, B. Trimarco, and G. Lembo. 2000. Insulin stimulated cardiac glucose uptake is impaired in spontaneously hypertensive rats: role of early steps of insulin signaling. J. Hypertens. 18:465473.

NRC. 1989. Nutrient Requirements of Dairy Cattle. 6th rev. ed. Natl. Acad. Press, Washington, DC. 
NRC. 2001. Nutrient Requirements of Dairy Cattle. 7th rev. ed. Natl. Acad. Press, Washington, DC.

O'Brien, M. D., R. P. Rhoads, S. R. Sanders, G. C. Duff, and L. H. Baumgard. 2010. Metabolic adaptations to heat stress in growing cattle. Domest. Anim. Endocrinol. 38:86-94.

Rhoads, M. L., J. W. Kim, R. J. Collier, B. A. Crooker, Y. R. Boisclair, L. H. Baumgard, and R. P. Rhoads. 2010. Effects of heat stress and nutrition on lactating Holstein cows: II. Aspects of hepatic growth hormone responsiveness. J. Dairy Sci. 93:170-179.

Rhoads, M. L., R. P. Rhoads, M. J. VanBaale, R. J. Collier, S. R. Sanders, W. J. Weber, B. A. Crooker, and L. H. Baumgard. 2009. Effects of heat stress and plane of nutrition on lactating Holstein cows: I. Production, metabolism, and aspects of circulating somatotropin. J. Dairy Sci. 92:1986-1997.

Rhoads, R. P., L. H. Baumgard, J. K. Suagee, and S. R. Sanders. 2013. Nutritional interventions to alleviate the negative consequences of heat stress. Adv. Nutr. 4:267-276.

Rhoads, R. P., J. W. Kim, M. E. Van Amburgh, R. A. Ehrhardt, S. J. Frank, and Y. R. Boisclair. 2007. Effect of nutrition on the GH responsiveness of liver and adipose tissue in dairy cows. J. Endocrinol. 195:49-58.

Rhoads, R. P., A. J. La Noce, J. B. Wheelock, and L. H. Baumgard. 2011. Alterations in expression of gluconeogenic genes during heat stress and exogenous bovine somatotropin administration. J. Dairy Sci. 94:1917-1921.

Saltiel, A. R., and C. R. Kahn. 2001. Insulin signalling and the regulation of glucose and lipid metabolism. Nature 414:799-806.

Sanz Fernandez, M. V., S. K. Stoakes, M. Abuajamieh, J. T. Seibert, J. S. Johnson, E. A. Horst, R. P. Rhoads, and L. H. Baumgard. 2015. Heat stress increases insulin sensitivity in pigs. Physiol. Rep. 3:e12478. http://dx.doi.org/10.14814/phy2.12478.
St-Pierre, N. R., B. Cobanov, and G. Schnitkey. 2003. Economic losses from heat stress by U.S. livestock industries. J. Dairy Sci. 86(E. Suppl.):E52-E77.

Taniguchi, C. M., B. Emanuelli, and C. R. Kahn. 2006. Critical nodes in signalling pathways: Insights into insulin action. Nat. Rev. Mol. Cell Biol. 7:85-96.

Wang, T., Q. Yu, J. Chen, B. Deng, L. Qian, and Y. Le. 2010. PP2A mediated AMPK inhibition promotes HSP70 expression in heat shock response. PLoS ONE 5:e13096. http://dx.doi.org/10.1371/ journal.pone.0013096.

Watson. R. T., and J. E. Pessin. 2006. Bridging the GAP between insulin signaling and GLUT4 translocation. Trends Biochem. Sci. $31: 215-222$.

West, J. W. 2003. Effects of heat-stress on production in dairy cattle. J. Dairy Sci. 86:2131-2144.

Wheelock, J. B., R. P. Rhoads, M. J. Vanbaale, S. R. Sanders, and L. H. Baumgard. 2010. Effects of heat stress on energetic metabolism in lactating Holstein cows. J. Dairy Sci. 93:644-655.

White, H. M., S. L. Koser, and S. S. Donkin. 2012. Regulation of bovine pyruvate carboxylase mRNA and promoter expression by thermal stress. J. Anim. Sci. 90:2979-2987.

Whiteman, E. L., H. Cho, and M. J. Birnbaum. 2002. Role of Akt/protein kinase B in metabolism. Trends Endocrinol. Metab. 13:444451.

Winder, W. W. 2001. Energy-sensing and signaling by AMP-activated protein kinase in skeletal muscle. J. Appl. Physiol. 91:1017-1028.

Zhao, F. Q., and A. F. Keating. 2007. Expression and regulation of glucose transporters in the bovine mammary gland. J. Dairy Sci. 90(E. Suppl. 1):E76-E86. 